\title{
Perception and Experiences of Sexual Harassment among Nursing Students
}

\section{in Alexandria, Egypt}

\author{
Rasha Abd El Hakim Abdou, Lecturer \\ Community Health Nursing, Faculty of Nursing, Alexandria University \\ Ola Mamdouh Abdel Wahed, Lecturer \\ Community Health Nursing, Faculty of Nursing, Alexandria University
}

\begin{abstract}
Sexual harassment is a widespread and serious problem in Egypt. Nursing profession has been reported to have the possibility of sexual harassment in the medical field because most of workers in nursing are still women in addition to their professional requirements. Objective: Assess the perception and experiences of Sexual Harassment among Nursing Students at the Faculty of Nursing, Alexandria University, Egypt. Setting: The study was carried out at the Faculty of Nursing, Alexandria University, Egypt. Subjects: Subjects of the study were 384 undergraduate nursing students selected from the four grades (192 males, 192 females) during the academic year 2014-2015. Tools: One tool was used for data collection namely nursing students' perception and experiences of sexual harassment structured interview schedule. It includes three parts covering data related to the students' personal and socio-demographic characteristics and their perception and experiences of sexual harassment. Results: Findings of the present study revealed that the vast majority of the female students experienced some forms of sexual harassment, while the majority of male students had committed harassment especially verbal form. In addition, less than half of the students had low perception about sexual harassment. Conclusion: The study concluded that sexual harassment is a prevalent problem among nursing students. Recommendations: Educational campaign to raise awareness toward the prevention and control of the problem is need.
\end{abstract}

Keywords: Harassment, Abuse, Nursing students.

\section{Introduction}

The issue of sexual harassment has only recently gained some serious attention from researchers, academics, policy makers and public. More than two decades ago, this phenomenon did not even have a name. Despite its visible existence, harassment has always plagued women for years because the society considered it more a private problem rather than a public issue ${ }^{(1)}$.

Sexual harassment has been described as any unwanted sexual conducts, requests deliberately perpetrated by the harasser for sexual favors or other physical and expressive behaviors of sexual nature that violate a person's body, privacy or feelings. It can take many different forms including verbal, physical and nonverbal (sexual).
Also, it may include one or more types at one time such as ogling, catcalls, stalking, following, sexual invites, touching, indecent exposure, sexual assault, and rape ${ }^{(2)}$.

Public recognition of the phenomenon becomes more prominent because sexual harassment has always been present. In fact, it is everywhere; at the workplace, schools and universities, in public places, transportations, streets, at home, online and all possible locations ${ }^{(3)}$.

It is possible that harassment may come from an individual or group of individuals targeted to one woman or to a group of women. The harasser can be a complete stranger or someone the victim knows; an employer, employee, coworker, customer, relative, family member, or a guest $^{(4,5)}$. 
Harassment is a silent but awful crime. Due to social stigma and lack of awareness, the victims of this crime do not raise their voice against it. But sexual harassment happens to be such a debilitating crime which eats up the very core of a human being. It hurts the woman's dignity, makes her feel powerless, helpless and often she may think herself responsible and deserving of such treatment. Moreover, sexual harassment cause serious physical, mental and emotional problems to the victims such as anxiety, fear, disturbed sleep, decreased appetite, headache, depression, lower self esteem, which may negatively affect occupational productivity, absenteeism, turnover and legal battle ${ }^{(1,6)}$.

Being subjected to sexually harassing behaviors is a particularly common experience for women. Given the pervasive and often highly public nature of these behaviors; it is perhaps not surprising that more than $80 \%$ of the Egyptian women reported that they were harassed according to a study conducted by the Egyptian Center for Women's Rights in $2013^{(7,8)}$.

There are many factors and causes for sexual harassment, some of them are associated with economic pressure which implied poverty and unemployment; social oppression as in marriage conditions and westernization $^{(9)}$.

Nursing profession has been reported to have the possibility of sexual harassment and sexual discrimination in the medical field because most of workers in nursing are still women. Moreover, nurses can be easily sexually harassed because of the professional characteristics that are nurses endure frequent occupational physical contact in the healthcare settings. As a result, the incidence of sexual harassment towards nurses is on the rise $\mathrm{e}^{(4,10)}$.

On the other hand, in order to be a nurse, it is necessary to complete a clinical practicum during the academic course. Clinical practice is carried out in various places, such as hospitals, local community public health centers, mental health centers, and so on. Nursing students, who have to meet people in various kinds of jobs, have to learn nursing not in protected schools but in unfamiliar clinical fields and subsequently could be easily exposed to the sexual harassment ${ }^{(10,11)}$.

Nursing students' especially female students may be considered as a high risk group for sexual harassment ${ }^{(12)}$. Sexual harassment is a very subjective feeling. It differs from one individual to another, as what constitute harassment for one individual, may not be the same for the other. For the students, the behavior can be entirely new. They may not even recognize the harassing behaviors and the harasser can take this as an advantage ${ }^{(13-15)}$. Therefore, it becomes very important to explore the perception and experiences of sexual harassment among students in the nursing profession for the purpose of prevention. Accordingly, this study is designed to describe the actual perception and experiences of sexual harassment of the nursing students.

\section{Aim of the Study}

\section{The aim of the study is to:}

Assess the perception and experience of harassment among nursing students at the Faculty of Nursing, Alexandria University.

\section{Research Questions:}

- What is the perceptual difference regarding harassment between male and female nursing students at the Faculty of Nursing, Alexandria University?

- What is the prevalence of sexual harassment experience among nursing students at the Faculty of Nursing, Alexandria University?

- What is the link between perception of harassment and its experience among nursing students? 


\section{Materials and Method}

Materials

Design: The descriptive comparative design was adopted to carry out this study.

Setting: The study was conducted at the Faculty of Nursing, Alexandria University.

\section{Subjects:}

- The sample size was estimate using Epi info 7 statistical program using the following parameters; Expected frequency $50 \%$, and $95 \%$ confidence level with 5\% maximum error. The minimum sample size estimated is 384 students.

- By using the proportional allocation method, $25 \%$ of undergraduate baccalaureate nursing students were selected randomly from the four grades, giving a total number of 384 students during the academic year 2014- 2015. Of these, 192 were males and 192 were females.

Tools: In order to collect the necessary data for the study, the following tool was used:

Tool I: Nursing students' perception and experiences of sexual harassment structured interview schedule

This was developed by the researchers to collect the necessary data from the students. It included the following parts:

First part: Socio demographic data about the students and their families such as age, residence, working status, parents' level of education, their occupation, marital status and social class which was assessed using Modified Fahmy and El-Sherbini Scale $(1983)^{(16)}$.

Second part: Students' perception about sexual harassment was assessed by 43items using a 3 points likert scale. It is clustered into the following domains; types of harassment (3 items), forms (9 items), risk factors (12 items), high risk group (7 items), possible places for harassment (7 items), common time for occurrence (3 items) and consequences (2 items). Response to each of the (43) items consist of three options: disagree/ undecided $=$ zero, and agree $=1$ creating a total score of $0-43$, which was converted into \% score and classified into the following:

- Low perception $\quad 0-21 \quad$ Less than 50\% - High perception 22-43 More than 50\%

Third part: Students' experiences of sexual harassment: It contained data about actual exposure to harassment incident in the previous years prior the current study, place and time of harassment, perpetrator characteristics, immediate and long term reactions to harassment, reporting of harassment and measures taken for protection against further harassment incidents.

\section{Method}

- Approval of the responsible authority was obtained from the Faculty of Nursing after explanation of the purpose of the study.

- After reviewing the recent relevant literatures, tool (I) was developed by the researchers, which were validated by jury of five experts in the field of Community Health Nursing. Their suggestions and recommendations were taken into consideration.

- Reliability for tool I (part two) was conducted using Cranach's alpha test 0.89 .

- A pilot study was carried out on 38 nursing students not included in the study subjects in order to ascertain the relevance, clarity and applicability of the tools, test wording of the questions and estimate the time required for the completion of the tools. Based on the obtained results, the necessary modifications were done. 
- Data was collected by the researchers during the academic year 2014-2015 over a period of 2 months (from March to April 2015).

\section{Ethical considerations:}

- Informed written consents were obtained from the students after a brief explanation of the purpose and nature of the research.

- The anonymity and confidentiality of responses, voluntary participation and right to refuse to participate in the study without any penalty were emphasized to the students.

\section{Statistical Analysis}

- The collected data were coded and analyzed using PC with the statistical package for social sciences (SPSS version 20) and tabulated. Frequencies and percentages were calculated.

- The level of significance selected for this study was $\mathrm{P}$ equal to or less than 0.05.It was used as the cut off value for statistical significance.

\section{Results}

Table (1) shows the nursing students' perceptions of sexual harassment. It was noticed that verbal assault was the first type of harassment as perceived by the majority of male and female students (86.5\% and $84.9 \%$ respectively), followed by physical assault $(78.1 \%$ and $81.8 \%$ respectively). While, nonverbal assault was stated by $71.9 \%$ of males compared to $66.7 \%$ of females.

Moreover, body touch was the most common perceived form of harassment among male students as mentioned by $88.0 \%$ of them compared to $91.7 \%$ of female students, while whistling was the most common form of harassment among females $(94.3 \%)$ compared to $69.3 \%$ of males. On the other hand, catcalls were the least perceived form of harassment as mentioned by $50.0 \%$ of males and $64.1 \%$ of females.

Regarding the risk factors of harassment, almost all (99.0\%) female students compared to $81.3 \%$ of male students stated that inadequate religious practices stand behind such behaviors. While, the vast majority $(96.3 \%)$ of males and $(78.6 \%)$ of females mentioned that girls' demeanor is a risk factor for harassment. A statistically significant difference was noticed between male and female students in relation to harassment's risk factors $\left(\mathrm{X}^{2}=86.03\right.$, $\mathrm{P}=0.000)$.

The same table reveals that young girls were at greater risk for harassment as stated by the majority of male and female students (89.6\% and $85.4 \%$ respectively). A statistically significant difference was found between them regarding risk group of harassment $\left(\mathrm{X}^{2}=17.34, \mathrm{P}=0.027\right)$.

Moreover, crowded places were the common place of harassment as perceived by the majority $(90.1 \%)$ of females compared to $78.1 \%$ of males. While, educational institutions were the least place for harassment as mentioned by $25.5 \%$ and $27.6 \%$ of male and female students respectively.

Additionally, more than three quarters of male and female students $(75.5 \%$ and $76.6 \%$ respectively) stated that night is the most common time for harassment.

Moreover, psychological problems such as anxiety and fear were the main consequences of harassment as mentioned by $94.8 \%$ of males compared to $95.8 \%$ of females with a statistically significant difference between them regarding consequences of harassment $\left(X^{2}=10.72\right.$, $\mathrm{P}=0.005)$.

Figure (1) portrays that less than half $(47.4 \%)$ of the students had low perception about harassment, this percentage composed of $42.7 \%$ of male students and $52.1 \%$ of female students. 
Table (2) reveals the experience of harassment among female students. It was found that almost all $(99.0 \%)$ of the students reported previous exposure to harassment, mainly verbal assault (83.2\%), furthermore, the majority $(82.6 \%)$ of them were exposed to harassment for three times and more.

The same table shows that the majority (87.4\%) of the victims were exposed to harassment at streets, while $27.4 \%$ of them at clinical areas. Moreover, the vast majority $(98.9 \%)$ of the victims had experienced harassment by strangers, followed by patients and their relatives (40.0\%). Additionally, harassment was occurred during the whole day but mainly at morning as reported by $71.6 \%$ of them.

The table indicated that more than three quarters $(78.9 \%)$ of the female victims experienced psychological consequences following harassment such as anxiety and fear, while those victims who reported no effects constituted $8.4 \%$ of them.

Moreover, in spite of that the vast majority $(98.9 \%)$ of the victims declared that they were dressed in conservative clothes during harassment time, $94.7 \%$ of them viewed themselves responsible for being harassed.

Regarding their reactions upon harassment, it was found that less than two fifth $(38.4 \%)$ of them got confused; while $60.5 \%$ of them had no reaction upon harassment because of fear of problems $(95.7 \%)$, and $7.0 \%$ of them viewed harassment as a common daily issue.

Lastly, following harassment, $79.5 \%$ of the victims dressed in conservative clothes as a self-protection measure, while, around one third (33.2\%) of them reported use of self-defense measures like spray.

Table (3) shows the distribution of male students according to their experience of being harasser. It was noticed that the majority $(93.2 \%)$ of male students had previously committed some forms of harassment, mainly verbal assault as mentioned by $93.9 \%$ of them, while, nonverbal assault was reported by none of them.

Furthermore, less than two thirds $(61.4 \%)$ of them committed harassment once, mainly at streets as stated by $96.6 \%$ of them and it was in the morning as reported by $72.1 \%$ of them.

Finally, the vast majority $(96.6 \%)$ of the male harassers perceived that it is the females' responsibility for provoking harassment.

Figure (2) illustrates the management measures of harassment. Enhancing religious awareness was the first measure reported by the vast majority $(95.3 \%)$ of females compared to $80.2 \%$ of the male students. While, enacting laws and penalties was mentioned by more than three quarters of male and female students $(78.1 \%$ and $82.3 \%$ respectively).

Table (4) portrays the relation between the female students' exposure to harassment and their socio-demographic characteristics. It was noticed that the younger the age of the females, the more the occurrence of harassment as it was more encountered among those aged less than 22 years as well as among unmarried students (100\%).

Moreover, female students who lived in urban areas experienced more harassment $(100 \%)$ than those in rural areas $(97.1 \%)$ with a significant relation between place of residence and harassment experience $\left(\mathrm{X}^{2}=9.066, \mathrm{P}=0.011\right)$.

Additionally, harassment was more prevalent among unveiled females (100\%) than veiled ones (98.9\%). Lastly, harassment was more encountered among those students in low and middle social class $(100 \%)$ with a statistically significant relation between social level and harassment experience $\quad\left(X^{2}=6.235\right.$, $\mathrm{P}=0.044)$.

Table (5) indicated the relation between male students' perpetration of harassment and their socio demographic characteristics. It was found that harassment perpetration 
was more encountered among those aged less than 20 years as well as among unmarried students (100\%).

Moreover, those students who lived in urban areas committed more harassment $(96.3 \%)$ than those in rural areas $(89.3 \%)$ with a significant relation between place of residence and harassment perpetration $\left(\mathrm{X}^{2}=8.679, \quad \mathrm{P}=0.013\right) . \quad$ Additionally, harassment perpetration was more encountered among those students with low social level $(93.8 \%)$ compared to those with high social level (92.3\%).

Table (6) shows the correlation analysis between experience and perpetration of harassment and perception of harassment. A significant correlation was found between perpetration of harassment and males' perception of harassment $(\mathrm{P}=0.046)$. While, a non-significant correlation was noticed between females' experiences of harassment and their perception of harassment $(\mathrm{P}=0.174)$.

\section{Discussion}

Violence affects the lives of millions of women worldwide, in all socioeconomic and educational classes. It cuts across cultural and religious barriers, impeding the rights of women to participate fully in the society $^{(1)}$. In recent years; there has been a greater concern about the problem of sexual harassment, its causes and consequences. According to a study done by the United Nations in Egypt in $2013^{(8),} 99.3 \%$ of the studied females reported being exposed to harassment in the previous year. This is supporting the results of the current study where the vast majority of the female students had a past experience with harassment (table 2).

Additionally, the current study reveals that the majority of the male students had committed harassing behaviors (table 3 ), which come in line with the results of Kenny K and Othman J (2011) ${ }^{(17)}$ and Sang $\mathrm{R}$ et al. $(2016)^{(18)}$ who found around two thirds of the college students had committed harassment within the college years. Moreover, according to the United Nation study in Egypt $2013^{(8)}$ the vast majority of the studied males reported committing some aspects of sexual harassment. This high percentage of harassers could be attributed to the culture belief system and its imposed gender role where the traditional cultural role for women is that of the wife and mother and the masculine role is that of men or the family provider. The social construction of masculinity implies that men should be dominant and defines certain behaviors as culturally acceptable for men such as use of power against women. In this view, gender is a status characteristic that accords men the power and dominance to harass women ${ }^{(2,6)}$.

Sexual harassment encompasses a vast range of behaviors that may be classified as verbal, physical and non-verbal ${ }^{(1)}$. The current study shows that the nursing students experienced three main types of harassment including verbal, physical and non-verbal assault. Moreover, the most prevalent type was verbal assault mainly whistling as experienced by the majority of female students as well as perpetrated by male students (table 2, 3). These figures support the students' perception about the type and forms of harassment where verbal abuse was the main type rated by them (table 1). This may be due to the fact that sexual assaults are unacceptable behaviors in our community and contradicted with the law and religion. Also, verbal assault may be accepted by cultural values and beliefs that are repeatedly communicated through the media. Oriental culture is supporting the use of verbal abuse as less harmful than physical abuse. These findings come in accordance with the results of Pina $\mathrm{A}$ and Gannon T (2012) ${ }^{(9)}$ and Witkowska E $(2012)^{(14)}$ who found that verbal harassment was the most common type of harassment among females.

On the other hand, the least experienced type of harassment was nonverbal (sexual) assault as reported by 
less than one tenth of the female students, while none of male students mentioned perpetration of such acts (table 2, 3). Although, these figures are contradicting the picture portrayed through the students' perception of nonverbal harassment which was mentioned by more than two thirds of them (table 1). These low percentages may be attributed to the shame and secrecy present around this issue and the great reluctance to speak out and report about such incidents and those who may report such incidents may be blamed and stigmatized $^{(19)}$. Similar results were noticed by Lee $\mathrm{S}$ et al. (2011) and Hassan R et al. $(2010)^{(11,20)}$.

Harassment is not limited to one place. Public places, transportations and shopping centers are usually crowded and with no or minimal guard supervision, which is considered a good media for practicing sexual harassment. The current study indicated that crowded places and public transportations were the most common places perceived by nursing students where they experienced and perpetrated harassment (table 1). Furthermore, the main perpetrator reported by the victims of the female students was strangers (table 2). The same results were reported by Desouky D and Marwan H (2013) ${ }^{(21)}$ who found that highest percentages of harassment were noted in public places and streets.

Moreover, the current study indicated that more than one quarter of the female students were harassed within the clinical areas mainly by the patients or their relatives as stated by less than half of them (table 2). These findings could be explained by the nature of nursing study, where nursing students have to deal with different patients and people in different clinical settings. They are usually in direct contacts with patients and their relatives which may subject them to higher chance of harassment. Accordingly, strategies for prevention and coping with harassment are needed for a safe educational environment, especially, in the clinical practices. It is also necessary to provide awareness session for the nurses who are at high risk for harassment for the recognition of the concept of harassment and what behaviors constitute harassment. This come in line with the results of Arulogun $\mathrm{O}$ et al. $(2013)^{(22)}$, and Lee $S$ et al. 2011 ${ }^{(11)}$ where more than half of nursing students were exposed to harassment in the clinical training whether by touch of the patients, their relatives or other health care team members.

Each victim of sexual assault responds uniquely and the recovery process is different for each individual. The victims may initially feel shocked, confused, and scared. They may deny or minimize the experience particularly when their attacker was an acquaintance or spouse. Some may reach out for assistance, while others may withdraw $^{(22,23)}$. These different reactions were reflected in the current study as less than two fifth of the female students reported confusion and fear upon harassment. The same results were reported by Lee $\mathrm{S}$ et al. 2011 ${ }^{(11)}$ (table 2).

The culture of silence is still prevailing in the Egyptian culture and it gives the harasser more power to do more harassment. This issue was highlighted by the present study where less than two thirds of the female victims reported doing nothing when they were confronted with harassment. They fear the impact of being harassed on their reputation as well as the reactions of people around them such as blaming and stigmatizing the victims or from the harasser himself (table 2). In line with this issue, Hassan R et al. (2010) ${ }^{(20)}$ and El Kaluby E $2014^{(24)}$ found that more than half of the harassment's victims reported fear of reporting about harassment and sexual violence because of cultural stigma associated with such issues. Contradictory findings were reported by Gurung A et al. 2016 ${ }^{(25)}$ who found that more than two thirds of the students reported the incidents to the authority. 
On the other hand, the current study showed that the majority of the female victims took protective measures against sexual harassment mainly adherence to wearing conservative clothes, although the vast majority of them viewed their clothes as being conservative at the time of harassment, which reflect the community strong belief about the link between the exposure to harassment and females' dress type (table 2). These findings are consistent with those of Arulogun O et al. (2013) ${ }^{(22)}$ and Street A et al. (2007) ${ }^{(26)}$ who found that harassment was strongly correlated with the style of clothes worn by the females.

Additionally, less than one quarter of the females decided not to go out late because more than three quarters of them perceived that night is the most common time for harassment, which contradicts the results of the same study as higher percentage of harassment incidents occurred in the morning (table 1, 2, 3). This comes in line with Lee $\mathrm{S}$ et al. $2011^{(11)}$ who found that nursing students experienced more harassment during their clinical practicum in the morning which endures frequent occupational contact within the health care system. Additional, Hassan $\mathrm{R}$ et al. $(2010)^{(20)}$ reported that less than two thirds of the female victims were harassed at early morning.

It is well documented that exposure of women to any form of violence had a great impact on their physical, social and psychological health ${ }^{(27,28)}$. The same picture was portrayed in the current study where more than three quarters of the victims experienced psychological consequences such as anger, fear, and anxiety, which came in line with the students' perspectives regarding the harassment consequences where psychological consequences entailed the highest percentages (table 1, 2). Evidence from other studies indicated that the psychological impact of harassment was greater than its physical consequences ${ }^{(6,8,9,11,20,29)}$.
It is evident that sexual harassment is a pervasive and widespread phenomenon of multidimensional causes or risk factors. The current study revealed a set of risk factors as perceived by the students mainly poverty, unemployment, late marriage, poor religious faith which all lead to sexual harassment (table 1). Moreover, the present study noticed that harassment was more prevalent among unmarried students and those of lower social class (table 4, 5). Additionally, less than two thirds of the male students stated that satisfaction of the sexual desire stands behind the widespread of harassment along with poverty and unemployment especially in the absence of laws and penalties against harassment (table 1). These results could be attributed to unemployment and poverty which interfered with traditional understandings of manhood and masculinity especially in the Arabian culture where man is viewed as the head of the family "the bread winner'. So, economic constraints make it difficult to fulfill his traditional masculine role. Participating in harassment is not necessarily intended to inflict physical, emotional, or psychological harm on women; rather it can be seen as an enactment of an internalized personal crisis brought about by an inability to get married within a society where marriage is a main initiation into adulthood ${ }^{(3,30)}$. Similar results were reported by Ismail $\mathrm{N}$ et al. (2007) and Banerjee A and Sharma B $(2011)^{(31,32)}$.

Furthermore, most of the male and female students blamed girls for their appearance and behaviors in public places and gave it as an excuse for the harassers. Also, they perceived it as the girls or women's responsibilities to provoke harassment (table 2,3). The same findings were reported by Arulogun $\mathrm{O}$ et al. (2013) and Banerjee A and Sharma B (2011) ${ }^{(22,32)}$ where less than half of the male participants viewed women as responsible for their harassment because of their dressing style. It is worth mentioning that changing the community's attitudes regarding harassment is needed especially among younger age. 
Perception is essential for the individual to comprehend his/her environment. It is the best action guidance and control device. Perception races right through the brain to evoke behavioral output. It does not stop somewhere, does not alter its course. The process of perception routinely alters what humans see and do. Perceiving an action activates the mental representation of this action which in turn will lead to performance of the action $^{(28)}$. Underlying the idea, the activation of a trait (e.g. aggressive) may in turn activate a number of behavioral representations characteristics of the trait involved (e.g., looking angrily, speaking with an offensive voice, and may even wanting to hit someone). Thus, the activation of a certain trait may lead to the activation of a set of concrete behavioral representations stored under it. This could explain the results of the current study where a significant correlation was noticed between male students' perception of harassment and its perpetration (table 6). In the same line, Fairchild K (2010) and Vohlidalova M (2011) mentioned that the magnitude of the behavioral effects simply mirrored the magnitude of the perceptual input $^{(33,34)}$.

\section{Conclusion}

Based upon the findings of the current study, it could be concluded that sexual harassment is awidespread phenomenon. It is conceptualized and experienced differently by male and female students. The vast majority of the female students experienced harassment, while the majority of male students had previously committed harassing behaviors. A strong relation was found between the perception of harassment and its experience.

\section{Recommendations}

- Raise awareness of the concept of sexual harassment. Awareness of the phenomenon is necessary to stand against it and take action.

- Observe good conduct and adhering to the principles of the Islamic and Christian religions which call for the respect and non-infringement on the freedom of others and to consider the female on the street as a mother, a sister or a wife.

- Promote positive images of women should be promoted and the importance of their participation in public space highlighted through mass media channels.

- Enhance community interventions and programs encouraging both women and men to stand up and report sexual harassment.

- Encourage the harassed to break the silence and eliminate the stigma around the issue.

- Made greater efforts to reach out younger people through unconventional methods such as media platforms to further encourage a debate about sexual harassment and the constructed images of women and their role in the society that leads to positive behavior change.

- Intensify research on the social, psychological, legal, and economic aspects of sexual harassment, with the goal of deepening the understanding of all facets of the problem.

- Enforce implementation of legislation and policies for the protection of women and the prosecution of perpetrators.

- Encourage programs directed to women empowerment to stand up for her rights in the community. 
Table (1): Distribution of the nursing students according to their perception of harassment

\begin{tabular}{|c|c|c|c|c|c|}
\hline \multirow{3}{*}{ Items } & \multicolumn{4}{|c|}{ Students' Sex } & \multirow{3}{*}{$\begin{array}{c}\text { Test of } \\
\text { Significance }\end{array}$} \\
\hline & \multicolumn{2}{|c|}{ Female $(\mathrm{N}=192)$} & \multicolumn{2}{|c|}{ Male $(\mathrm{N}=192)$} & \\
\hline & No. & $\%$ & No. & $\%$ & \\
\hline \multicolumn{6}{|l|}{ Type of harassment* } \\
\hline - Verbal & 163 & 84.9 & 166 & 86.5 & $X^{2}=0.523$ \\
\hline - Physical & 157 & 81.8 & 150 & 78.1 & $\mathrm{P}=0.769$ \\
\hline - Non verbal & 128 & 66.7 & 138 & 71.9 & \\
\hline \multicolumn{6}{|l|}{ Forms of harassment* } \\
\hline - Whistling/ verbal abuse & 181 & 94.3 & 133 & 69.3 & $X^{2}=10.18$ \\
\hline - Body touch / pinching & 176 & 91.7 & 169 & 88.0 & $\mathrm{P}=0.253$ \\
\hline - Indecent exposure & 163 & 84.9 & 110 & 57.3 & \\
\hline - Following/ stalking & 160 & 83.3 & 108 & 56.3 & \\
\hline - Sexual gestures & 150 & 78.1 & 127 & 66.1 & \\
\hline - Offensive emails & 136 & 70.8 & 98 & 51.0 & \\
\hline - Ogling/ staring & 135 & 70.3 & 124 & 64.6 & \\
\hline - Hanging pornography & 130 & 67.7 & 117 & 60.9 & \\
\hline - Catcalls & 123 & 64.1 & 96 & 50.0 & \\
\hline \multicolumn{6}{|c|}{ Risk factors / causes of harassment $*$} \\
\hline - Poor religion & 190 & 99.0 & 156 & 81.3 & $X^{2}=86.03$ \\
\hline - Absence of laws & 166 & 86.5 & 120 & 62.5 & $\mathrm{P}=0.000 * *$ \\
\hline - Media pornography & 165 & 85.9 & 106 & 55.2 & \\
\hline - Girls demeanor & 151 & 78.6 & 185 & 96.3 & \\
\hline - Overcrowding & 130 & 67.7 & 65 & 33.9 & \\
\hline - Late marriage & 125 & 65.1 & 119 & 62.0 & \\
\hline - Absence of police in streets & 117 & 60.9 & 82 & 42.7 & \\
\hline - Youth unemployment & 107 & 55.7 & 97 & 50.5 & \\
\hline - Poverty & 84 & 43.8 & 52 & 27.1 & \\
\hline - Sexual desire satisfaction & 75 & 39.1 & 122 & 63.5 & \\
\hline - Poor child raising & 28 & 14.6 & 21 & 10.9 & \\
\hline - Have fun & 8 & 4.2 & 42 & 21.9 & \\
\hline \multicolumn{6}{|c|}{ High risk group of harassment $*$} \\
\hline - Young girls & 164 & 85.4 & 172 & 89.6 & $X^{2}=17.34$ \\
\hline - Working girls / women & 150 & 78.1 & 160 & 83.3 & $\mathrm{P}=0.027 * *$ \\
\hline - Unveiled girls/ women & 116 & 60.4 & 98 & 51.0 & \\
\hline - Adolescents girls & 110 & 57.3 & 123 & 64.1 & \\
\hline - Adult women & 83 & 43.2 & 67 & 34.9 & \\
\hline - Disabled girls / women & 43 & 22.4 & 32 & 16.7 & \\
\hline - Elderly women & 40 & 20.8 & 23 & 12.0 & \\
\hline \multicolumn{6}{|c|}{ Common places where harassment can occur* } \\
\hline - Crowded places & 173 & 90.1 & 150 & 78.1 & $X^{2}=10.61$ \\
\hline - Transportation & 158 & 82.3 & 119 & 62.0 & $\mathrm{P}=0.101$ \\
\hline - Streets & 162 & 84.4 & 125 & 65.1 & \\
\hline - Phone & 136 & 70.8 & 95 & 49.5 & \\
\hline - Deserted places & 98 & 51.0 & 106 & 55.2 & \\
\hline - Internet & 77 & 40.1 & 88 & 45.8 & \\
\hline - Educational institutions & 53 & 27.6 & 49 & 25.5 & \\
\hline
\end{tabular}


Table (1): (Continued)

\begin{tabular}{|c|c|c|c|c|c|}
\hline \multirow{3}{*}{ Items } & \multicolumn{4}{|c|}{ Students' Sex } & \multirow{3}{*}{$\begin{array}{c}\text { Test of } \\
\text { Significance }\end{array}$} \\
\hline & \multicolumn{2}{|c|}{ Female $(N=192)$} & \multicolumn{2}{|c|}{ Male $(\mathrm{N}=192)$} & \\
\hline & No. & $\%$ & No. & $\%$ & \\
\hline \multicolumn{6}{|c|}{ Periods where harassment can occur* } \\
\hline - Morning & 109 & 56.8 & 98 & 51.0 & $\mathrm{X}^{2}=0.263$ \\
\hline - Evening & 117 & 60.9 & 110 & 57.3 & $\mathrm{P}=0.876$ \\
\hline - Night & 147 & 76.6 & 145 & 75.5 & \\
\hline \multicolumn{6}{|c|}{ Consequences of harassment* } \\
\hline - Psychological problems & 184 & 95.8 & 182 & 94.8 & $X^{2}=10.72$ \\
\hline - Physical problems & 91 & 47.4 & 104 & 54.2 & $\mathrm{P}=0.005^{* *}$ \\
\hline
\end{tabular}

* Multiple responses are allowed

** Significant at $\mathrm{P} \leq 0.05$

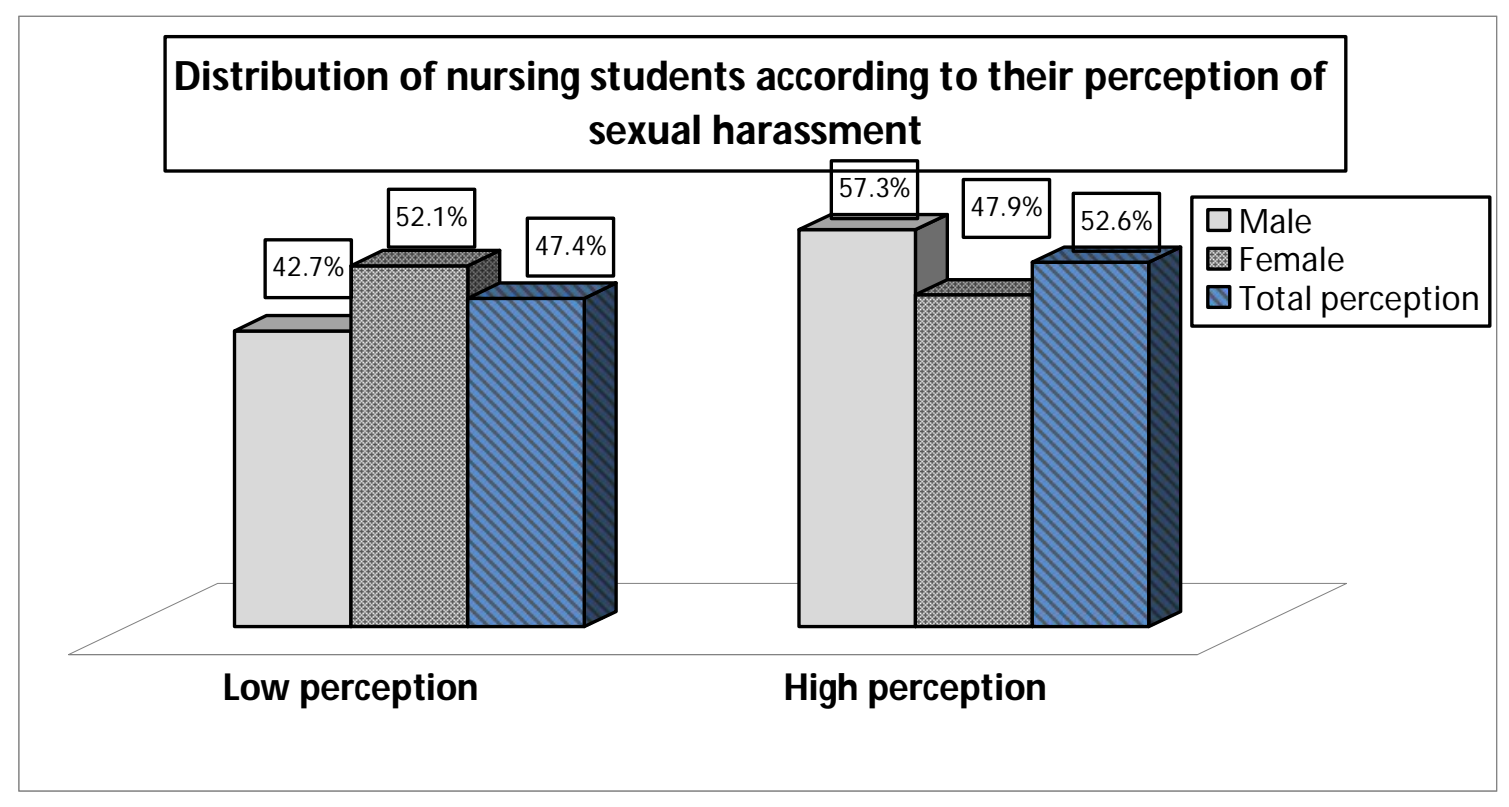

Figure (1): Distribution of nursing students according to their total perception of harassment 
Table (2): Distribution of the female students according to their experience of harassment

\begin{tabular}{|c|c|c|}
\hline \multirow[t]{2}{*}{ Items } & \multicolumn{2}{|c|}{$\begin{array}{c}\text { Total } \\
\mathrm{N}=192\end{array}$} \\
\hline & No. & $\%$ \\
\hline \multicolumn{3}{|l|}{ Experience of harassment } \\
\hline - Yes & 190 & 99.0 \\
\hline$-\mathrm{No}$ & 2 & 1.0 \\
\hline Type of harassment* & \multicolumn{2}{|c|}{$\mathbf{N}=190$} \\
\hline - Verbal & 158 & 83.2 \\
\hline - Physical & 78 & 41.1 \\
\hline - Non verbal & 31 & 16.3 \\
\hline \multicolumn{3}{|l|}{ Frequency of harassment } \\
\hline - Once & 12 & 6.3 \\
\hline - Twice & 21 & 11.1 \\
\hline - Three times and more & 157 & 82.6 \\
\hline \multicolumn{3}{|c|}{ Place where harassment occurred* } \\
\hline - Streets & 166 & 87.4 \\
\hline - Transportations & 151 & 79.5 \\
\hline - Public places & 69 & 36.3 \\
\hline - Clinical areas/work place & 52 & 27.4 \\
\hline - Phone & 49 & 25.8 \\
\hline - Internet & 35 & 18.4 \\
\hline - Home & 23 & 12.1 \\
\hline - School/ faculty & 12 & 6.3 \\
\hline \multicolumn{3}{|l|}{ Time of harassment* } \\
\hline - Morning & 136 & 71.6 \\
\hline - Evening & 110 & 57.9 \\
\hline - Night & 59 & 31.1 \\
\hline \multicolumn{3}{|l|}{ Perpetrators of harassment* } \\
\hline - Stranger & 188 & 98.9 \\
\hline - Patients / patients' relatives & 76 & 40.0 \\
\hline - Colleagues & 43 & 22.6 \\
\hline - Relatives & 33 & 17.4 \\
\hline - Work supervisors & 6 & 3.2 \\
\hline \multicolumn{3}{|l|}{ Consequences of harassment* } \\
\hline - Psychological & 150 & 78.9 \\
\hline - Physical & 28 & 14.7 \\
\hline - No effect & 16 & 8.4 \\
\hline \multicolumn{3}{|c|}{ View of personal clothes at harassment time } \\
\hline - Conservative & 188 & 98.9 \\
\hline - Not conservative & 2 & 1.1 \\
\hline \multicolumn{3}{|c|}{ Own responsibility of harassment occurrence } \\
\hline - Yes & 180 & 94.7 \\
\hline$-\mathrm{No}$ & 10 & 5.3 \\
\hline
\end{tabular}

* Multiple responses are allowed

** Significant at $\mathrm{P} \leq 0.05$ 
Table (2): (Continued)

\begin{tabular}{|c|c|c|}
\hline \multirow[t]{2}{*}{ Items } & \multicolumn{2}{|c|}{$\begin{array}{c}\text { Total } \\
\mathrm{N}=192\end{array}$} \\
\hline & No. & $\%$ \\
\hline Reactions to harassment* & \multicolumn{2}{|c|}{$\mathbf{N}=190$} \\
\hline - No reaction & 115 & 60.5 \\
\hline - Got confused & 73 & 38.4 \\
\hline - Fear and run away & 62 & 32.6 \\
\hline - Verbal assault of perpetrator & 14 & 7.4 \\
\hline - Physical assault of perpetrator & 8 & 4.2 \\
\hline - Ask help from bypass & 6 & 3.2 \\
\hline - Ask police help & 2 & 1.0 \\
\hline Causes of no reaction to harassment* & \multicolumn{2}{|c|}{$\mathbf{N}=115$} \\
\hline - Fear of problems & 110 & 95.7 \\
\hline - Embarrassment & 79 & 68.7 \\
\hline - Fear of scandal & 52 & 45.2 \\
\hline - Believe no one would help & 43 & 37.4 \\
\hline - Common daily issue & 8 & 7.0 \\
\hline Self protection measures of harassment* & \multicolumn{2}{|c|}{$\mathrm{N}=190$} \\
\hline - Dress in conservative clothes & 151 & 79.5 \\
\hline - Never being late outdoor & 116 & 61.0 \\
\hline - Avoid crowded places & 80 & 42.1 \\
\hline - Use of self defense measures & 63 & 33.2 \\
\hline - Avoid being near men & 56 & 29.5 \\
\hline - Never go out late & 45 & 23.7 \\
\hline - Avoid public transportation & 28 & 14.7 \\
\hline - No action taken & 19 & 10.0 \\
\hline
\end{tabular}

* Multiple responses are allowed 
Table (3): Distribution of the male students according to their experience of being harasser

\begin{tabular}{|c|c|c|}
\hline \multirow[t]{2}{*}{ Items } & \multicolumn{2}{|c|}{$\begin{array}{c}\text { Total } \\
\mathrm{N}=192\end{array}$} \\
\hline & No. & $\%$ \\
\hline \multicolumn{3}{|l|}{ Committing harassment } \\
\hline - Yes & 179 & 93.2 \\
\hline - No & 13 & 6.8 \\
\hline Type of harassment* & \multicolumn{2}{|c|}{$\mathrm{N}=179$} \\
\hline - Verbal & 168 & 93.9 \\
\hline - Physical & 12 & 6.7 \\
\hline - Non verbal & 0 & 0.0 \\
\hline \multicolumn{3}{|c|}{ Number of times of harassment } \\
\hline - Once & 110 & 61.4 \\
\hline - Twice & 65 & 36.3 \\
\hline - Three times or more & 4 & 2.2 \\
\hline \multicolumn{3}{|c|}{ Place where harassment occurred* } \\
\hline - Streets & 173 & 96.6 \\
\hline - Public places & 61 & 34.1 \\
\hline - Internet & 53 & 29.6 \\
\hline - Transportations & 33 & 18.4 \\
\hline - Phone & 13 & 7.3 \\
\hline - Clinical areas/work place & 3 & 1.7 \\
\hline - Home & 2 & 1.1 \\
\hline - School/ faculty & 2 & 1.1 \\
\hline \multicolumn{3}{|l|}{ Time of harassment* } \\
\hline - Morning & 129 & 72.1 \\
\hline - Evening & 78 & 43.6 \\
\hline - Night & 42 & 23.5 \\
\hline \multicolumn{3}{|c|}{ Think it is females' responsibility of harassment occurrence } \\
\hline - Yes & 173 & 96.6 \\
\hline - No & 6 & 3.4 \\
\hline
\end{tabular}

* Multiple responses are allowed 


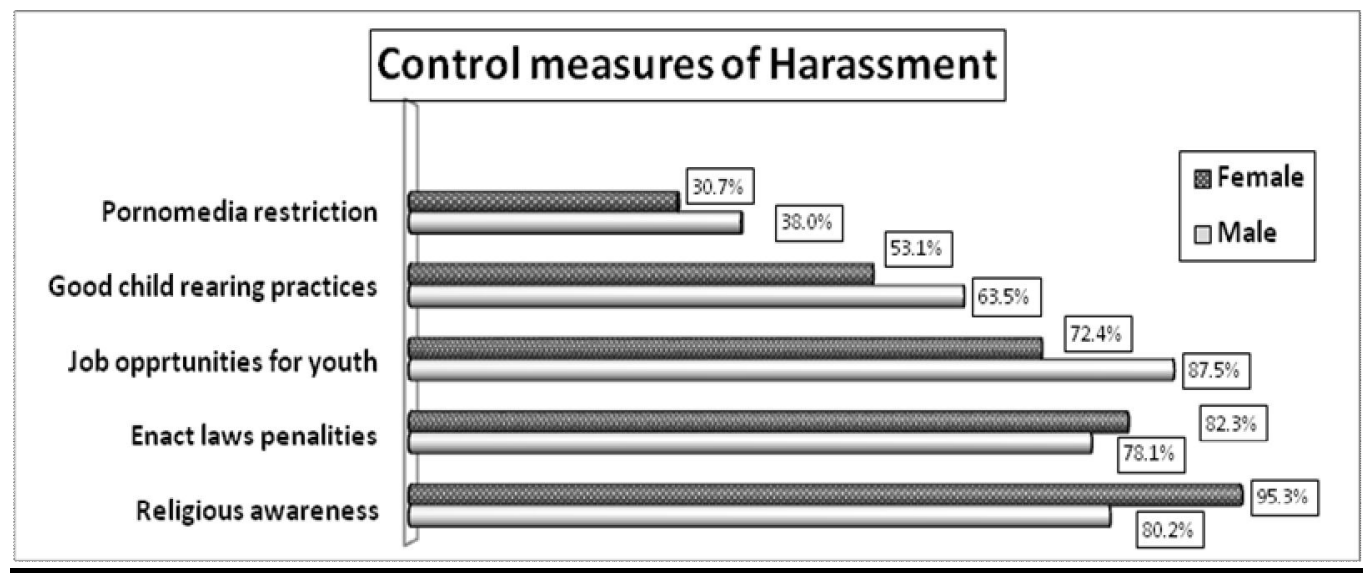

Figure (2): Control measures of harassment as reported by the nursing students

Table (4): The relation between the female students' exposure to harassment and their socio demographic characteristics

\begin{tabular}{|c|c|c|c|c|c|c|}
\hline \multirow{3}{*}{ Items } & \multicolumn{4}{|c|}{ Exposure to harassment } & \multirow{3}{*}{$\begin{array}{c}\text { Total } \\
(\mathrm{N}=192)\end{array}$} & \multirow{3}{*}{ Test of Significance } \\
\hline & \multicolumn{2}{|c|}{$\begin{array}{c}\text { Yes } \\
(\mathrm{N}=190)\end{array}$} & \multicolumn{2}{|c|}{$\begin{array}{c}\text { No } \\
(\mathrm{N}=2)\end{array}$} & & \\
\hline & No. & $\%$ & No. & $\%$ & & \\
\hline \multicolumn{7}{|l|}{ Age (years) } \\
\hline$-18-$ & 48 & 100.0 & 0 & 0.0 & 48 & \multirow{3}{*}{$\begin{array}{c}X^{2}=2.544 \\
P=0.280\end{array}$} \\
\hline$-20-$ & 59 & 100.0 & 0 & 0.0 & 59 & \\
\hline$-22+$ & 83 & 97.6 & 2 & 2.4 & 85 & \\
\hline \multicolumn{7}{|l|}{ Marital status } \\
\hline - Married & 1 & 50.0 & 1 & 50.0 & 2 & $X^{2}=0.523$ \\
\hline - Not married & 190 & 100.0 & 0 & 0.0 & 190 & $P=0.769$ \\
\hline \multicolumn{7}{|c|}{ Place of residence } \\
\hline - Urban & 123 & 100.0 & 0 & 0.0 & 123 & $X^{2}=9.066$ \\
\hline - Non urban & 67 & 97.1 & 2 & 2.9 & 69 & $\mathrm{P}=0.011 * *$ \\
\hline \multicolumn{7}{|l|}{ Dress type } \\
\hline - Veiled & 187 & 98.9 & 2 & 1.1 & 189 & $X^{2}=0.222$ \\
\hline - Unveiled & 3 & 100.0 & 0 & 0.0 & 3 & $\mathrm{P}=0.895$ \\
\hline \multicolumn{7}{|c|}{ Family social level } \\
\hline - Low & 105 & 100.0 & 0 & 0.0 & 105 & $X^{2}=6.235$ \\
\hline - Middle & 40 & 100.0 & 0 & 0.0 & 40 & $\mathrm{P}=0.044 * *$ \\
\hline - High & 45 & 95.7 & 2 & 4.3 & 47 & \\
\hline
\end{tabular}

** Significant at $\mathrm{P} \leq 0.05$ 
Table (5): The relation between the male students' perpetration of harassment and their socio demographic characteristics

\begin{tabular}{|c|c|c|c|c|c|c|}
\hline \multirow{3}{*}{ Items } & \multicolumn{4}{|c|}{ Perpetration of harassment } & \multirow{3}{*}{$\begin{array}{c}\text { Total } \\
(\mathrm{N}=192)\end{array}$} & \multirow{3}{*}{ Test of Significance } \\
\hline & \multicolumn{2}{|c|}{$\begin{array}{c}\text { Yes } \\
(\mathrm{N}=179)\end{array}$} & \multicolumn{2}{|c|}{$\begin{array}{c}\text { No } \\
(\mathrm{N}=13)\end{array}$} & & \\
\hline & No. & $\%$ & No. & $\%$ & & \\
\hline \multicolumn{7}{|l|}{ Age (years) } \\
\hline$-18-$ & 4 & 100.0 & 0 & 0.0 & 4 & \multirow{3}{*}{$\begin{array}{c}X^{2}=3.465 \\
P=0.177\end{array}$} \\
\hline$-20-$ & 142 & 97.6 & 12 & 2.4 & 154 & \\
\hline$-22+$ & 33 & 97.1 & 1 & 2.9 & 34 & \\
\hline \multicolumn{7}{|l|}{ Marital status } \\
\hline - Married & 0 & 0.0 & 8 & 100.0 & 8 & $X^{2}=0.523$ \\
\hline - Not married & 179 & 97.3 & 5 & 2.7 & 184 & $P=0.769$ \\
\hline \multicolumn{7}{|c|}{ Place of residence } \\
\hline - Urban & 104 & 96.3 & 4 & 3.7 & 108 & $X^{2}=8.679$ \\
\hline - Non urban & 75 & 89.3 & 9 & 10.7 & 84 & $\mathrm{P}=0.013 * *$ \\
\hline \multicolumn{7}{|c|}{ Family social level } \\
\hline - Low & 90 & 93.8 & 6 & 6.2 & 96 & $X^{2}=1.775$ \\
\hline - Middle & 41 & 93.2 & 3 & 6.8 & 44 & $P=0.620$ \\
\hline - High & 48 & 92.3 & 4 & 7.7 & 52 & \\
\hline
\end{tabular}

** Significant at $\mathrm{P} \leq 0.05$

Table (6): Correlation between students' perception of harassment and its experience and perpetration

\begin{tabular}{|l|c|c||}
\hline \hline Statistical Test Pearson's r & Correlation Coefficient & Significance \\
\hline - Males' perception of harassment & 0.144 & $0.046^{*}$ \\
\hline - Females' perception of harassment & 0.98 & 0.174 \\
\hline
\end{tabular}

* Significant at $\mathrm{P} \leq 0.05$ 


\section{References}

1. Neilson M, Bjorkela B, Notelaers G, Einarsen S. Sexual Harassment: Prevalence, Outcomes and Gender Differences Assessed by Three Different Estimation Methods. Journal of Aggression, Maltreatment \& Trauma 2010; 19(3): 252-74.

2. Nyende P. Experience of Sexual Harassment of Female and Male Students at Makerere University. Makerere University Research Journal 2006; 1(2): 125-32.

3. Goldtein S, Malanchuk O, Davis P, Eccles J. Risk Factors of Sexual Harassment by Peers: A longitudinal Investigation of African American and European American Adolescents. Journal of Research on Adolescence 2007; 17(2):285-300.

4. Fute M, Mengesha Z, Wakgari N, Tessema G. High Prevalence of Workplace Violence Among Nurses Working at Public Health Facilities in Southern Ethiopia. BMC Nursing 2015; 14(9): 1-5.

5. Walsh M, Duffy J, Gallagher J. A more Accurate Approach to Measure the Prevalence of Sexual Harassment among High School Students. Canadian Journal of Behavioral Science 2007; 39(2):110-8.

6. Marican S, Abrahma A. Experience, Effects and Combating sexual Harassment at Workplace: A Malaysian Case. International Journal of Innovations in Business 2012; 1(1): 95112.

7. International Development Research Center (IDRC). Towards A Safer City: Sexual Harassment in Greater Cairo. Egypt: IDRC; 2014. Available at: http://www.harassmap.org/reports/en/. (Retrieved on: 26/11/2014).
8. United Nations Entity for Gender Equality and Empowerment of Women. Study on Ways and Methods to Eliminate Sexual Harassment in Egypt. Egypt: UN; 2013. Available at: http://www.dgvn.de /SH-Study-EgyEn/pdf/. (Retrieved on: 15/10/2014).

9. Pina A, Gannon T. An Overview of the Literature on Antecedents, Perceptions and Behavioral Consequences of Sexual Harassment. Journal of Sexual Aggression 2012; 18(2): 209-32.

10. Balamurugan G, Jose T, Nandakumar P. Patients' Violence towards Nurses. A Questionnaire Survey. International Journal of Nursing 2012; 1(1): 1-7.

11. Lee S, Song J, Kim S. Experience and Perception of Sexual Harassment during Clinical Practice of Korean Nursing Students. Asian Nursing Research 2011; 5: 170-6.

12. Nagata $S$, Sekimoto $M$, Koyama $H$, Yamamoto W, Gata E. Medical Students Abuse During Clinical Clerkships in Japan. Journal of General Internal Medicine 2006; 21: 212-8.

13. Menon A, Shilalukey M, Siziya S, Ndubani P, Musepa M. University Students' Perceptive of Sexual Harassment: A Case Study of the University of Zambia. Medical Journal of Zambia 2009; 36(2): 35-91.

14. Witkowska E. Perceptions of Sexual Harassment in Swedish High Schools: Experiences and School Environment Problems. European Journal of Public Health 2012; 15(1): 78-85.

15. Bursik K, Geffer J. Still Stable After All These Years: Perceptions of Sexual Harassment in Academic Contexts. The Journal of Social Psychology 2011; 151(3): 331-49.

16. Fahmy S, El-Sherbini AF. Determining simple parameters for social 
classifications for health research (1983). Bulletin of the High Institute of Public Health 2005.

17. Kenny K, Othman J. Sexual Harassment: A Study to Examine the Predictors that Leads Men to Sexually Harass. International Journal of Humanities and Social Science 2011; 1(12): 208-17.

18. Sang R, Kemboi J, Omenge R. Sexual Harassment Among University Students within University of Eldoret, UasinGishu Country, Kenya. IOSR Journal of Dental and Medical Science 2016; 15(8): 142-51.

19. Jone O. Gender Differences in Perception of Sexual Harassment among University Students. Gender and Behavior 2012; 10(1): 4358-69.

20. Hassan R, Shoukry A, Abulkomsan N. Clouds in Egypt's Sky: Sexual Harassment: From Verbal Harassment to Rape. Available at: http://Egypt.unfpa.org/publication/2010. pdf.

21. Desouky D, Marwan H. Awareness and Experience of Sexual Harassment among Menoufia University Students. Asia Journal of Public Health 2013; 4(1): 16-26.

22. Arulogun O, Omotosho I, Titiloye M. Experience of Sexual Harassment and Coping Strategies among Students of the School of Nursing of a Tertiary Hospital in Southwest Nigeria. International Journal of Nursing and Midwifery 2013; 5(4): 70-5.

23. Shaban I, Khater W, Akhu-Zaheya L. Undergraduate Nursing Students' Stress Sources and Coping Behaviours during Their Initial Period of Clinical Training: A Jordanian Perspectives. Nursing Education in Practice 2012; 12: 204-9.
24. El Kaluby E. Comparative Study of Violence Among Adolescents in Urban, Rural and Squatter Areas in Alexandria. Unpublished $\mathrm{PhD}$ Thesis, Faculty of Nursing, Alexandria University, Egypt, 2014.

25. Gurung A, Priyadarshini S, Margaret B. Perception of Sexual Harassment among the Undergraduate Students. Manipal Journal of Nursing and Health Science 2016; 2(1): 46-51.

26. Street A, Gradus J, Stafford J, Kelly K. Gender Differences in the Experiences of Sexual Harassment: Data from a Male Dominated Environment. Journal of Consulting and Clinical Psychology 2007; 75: 464-74.

27. Stanhope M, Lancaster T. Public Health Nursing: Population centered health care in the community. $7^{\text {th }}$ ed, USA: Mosby Company; 2008.

28. Patricia G, Winifred Z, Karen A. Psychiatric Mental Health Nursing: An Introduction to Theory and Practice. $7^{\text {th }}$ ed, Boston: Jones and Beatle Publisher; 2008.

29. Chiodo D, Wolfe A, Crooks C, Hughes R, Jaffe P. Impact of Sexual Harassment Victimization by Peers on Subsequent Adolescent Victimization and Adjustment: a Longitudinal Study. Journal of Adolescent Health 2009; 45(3): 246-52.

30. Mareah F. Street Harassment in Cairo: A symptom of Disintegrating Social Structures. The African Anthropologist 2008; 15(1): 1-20.

31. Ismail N, Chee L, Bee C. Factors Influencing Sexual Harassment in the Malaysian Workplace. Asian Academy of Management Journal 2007; 12(15): 15-31. 
32. Banerjee A, Sharma B. Gender Differences in Perception of Workplace Sexual Harassment among Future Professionals. Indian Psychiatry Journal 2011; 20 (1): 21-4.

33. Fairchild K. Context Effects on Women's' Perceptions of Stranger
Harassment. Sexuality \& Culture 2010; 14: 191-216.

34. Vohlidalova M. The Perception and Construction of Sexual Harassment by Czech University Students. Czech Sociological Review 2011; 47(6): 111947. 